\title{
25-Hydroxyvitamin D status, metabolic syndrome and insulin resistance in preadolescent child in Korea
}

\author{
Hae Soon Kim ${ }^{1 *}$, Hye Ah Lee ${ }^{2}$, Young Ju Kim³ ${ }^{3}$ Eun Ae Park', Hyesook Park ${ }^{2}$ \\ From 7th APPES Biennial Scientific Meeting \\ Nusa Dua, Bali. 14-17 November 2012
}

\section{Background and aims}

The lower 25-Hydroxyvitamin $\mathrm{D}(25(\mathrm{OH}) \mathrm{D})$ is being suggested as a risk factor for Type 2 diabetes, but there is not well construed for its relationship. Therefore, we aimed to assess the association among $25(\mathrm{OH}) \mathrm{D}$ level, metabolic syndrome components [Waist circumference (WC), Blood pressure, Triglycerides, Glucose, HighDensity lipoprotein Cholesterol], and insulin resistance indices [homeostasis model assessment-insulin resistance, quantitative insulin-sensitivity resistance, glucose to insulin ratio] among preadolescent child.

\section{Methods}

We followed up 221 subjects from July to August 2011 aged 7 to 9 child, who were part of Ewha Birth \& Growth Cohort study, Seoul, Korea, which is a prospective cohort established 2001-2006. We investigated the associations among vitamin D level in blood, metabolic syndrome components, and insulin resistance using multivariate regression analysis adjusted for sex, age, birth weight, calories, and BMI z score.

\section{Results}

$38(17.2 \%)$ child were deficiency $(<20 \mathrm{ng} / \mathrm{mL})$ for vitamin $\mathrm{D}$ level, and its prevalence was more higher in boys (25.2\%) than girls (8.1\%). There was significant relationship between $25(\mathrm{OH}) \mathrm{D}$ and triglycerides $(\beta=-0.01$, $p=0.04$ ) adjusted for sex, age, birth weight, calories, and BMI z score. WC was also negatively associated with 25 $(\mathrm{OH}) \mathrm{D}(\beta=-0.13, p=0.07)$ with cofactors, although its relationship was shown the marginal boundary. But, other features were not associated with $25(\mathrm{OH}) \mathrm{D}$. When regarding the criteria for metabolic components, those who were more than WC $90 \%$ tile had higher frequency in deficient group than in sufficient group, but distribution of metabolic components among 25(OH)D status was no significant difference.

\section{Conclusions}

The lower $25(\mathrm{OH}) \mathrm{D}$ level may contribute to the association with some of metabolic components in general preadolescent child, but further study is needed to explore the relationship with insulin resistance.

\section{Acknowledgements}

This work was supported by National Research Foundation of Korea Grant funded by the Korean Government (2010-0026225).

\section{Authors' details}

'Department of Pediatrics, School of Medicine, Ewha Womans University, Seoul, Korea. ${ }^{2}$ Department of preventive medicine, School of Medicine, Ewha Womans University, Seoul, Korea. ${ }^{3}$ Obstetrics and Gynecology, School of Medicine, Ewha Womans University, Seoul, Korea.

Published: 3 October 2013

doi:10.1186/1687-9856-2013-S1-P96

Cite this article as: Kim et al:: 25-Hydroxyvitamin D status, metabolic syndrome and insulin resistance in preadolescent child in Korea. International Journal of Pediatric Endocrinology 2013 2013(Suppl 1):P96. 